Article

\title{
Model Matching Theory: A Framework for Examining the Alignment between Game Mechanics and Mental Models
}

\author{
Rory McGloin ${ }^{1}$, Joe A. Wasserman ${ }^{2, *}$, Andy Boyan ${ }^{3}$ \\ ${ }^{1}$ Department of Communication, University of Connecticut, Storrs, CT 06269, USA; E-Mail: rory.mcgloin@uconn.edu \\ 2 Department of Communication Studies, West Virginia University, Morgantown, WV 26501, USA; \\ E-Mail: jowasserman@mix.wvu.edu \\ ${ }^{3}$ Communication Studies Department, Albion College, Albion, MI 49224, USA; E-Mail: aboyan@albion.edu \\ * Corresponding author
}

Submitted: 26 December 2017 | Accepted: 2 April 2018 | Published: 7 June 2018

\begin{abstract}
The primary aim of this article is to provide a comprehensive review and elaboration of model matching and its theoretical propositions. Model matching explains and predicts individuals' outcomes related to gameplay by focusing on the interrelationships among games' systems of mechanics, relevant situations external to the game, and players' mental models. Formalizing model matching theory in this way provides researchers a unified explanation for game-based learning, game performance, and related gameplay outcomes while also providing a theory-based direction for advancing the study of games more broadly. The propositions explicated in this article are intended to serve as the primary tenets of model matching theory. Considerations for how these propositions may be tested in future games studies research are discussed.
\end{abstract}

\section{Keywords}

game-based learning; game mechanics; media effects; mental models; model matching; skill acquisition; video games

\section{Issue}

This article is part of the issue "Games Matter? Current Theories and Studies on Digital Games", edited by Julia Kneer (Erasmus University Rotterdam, The Netherlands) and Ruud Jacobs (University of Twente, The Netherlands).

(C) 2018 by the authors; licensee Cogitatio (Lisbon, Portugal). This article is licensed under a Creative Commons Attribution 4.0 International License (CC BY).

\section{Introduction}

Games, whether analog or digital, are governed by sets of game mechanics through which players attempt to overcome the game's challenges. Players' interactions with a game's mechanics provide a starting point from which researchers can examine outcomes related to gameplay, including developing general cognitive abilities (Green, 2018), learning academic content (Laski \& Siegler, 2014), enjoyment (Oliver et al., 2016), feelings of aggression or hostility (McGloin, Farrar, \& Fishlock, 2015), and/or experiences of direct skill transfer from gameplay to external situations (Korteling, Helsdingen, \& Sluimer, 2017).

However, players' in-game decision-making is influenced by more than just a game's mechanics. In ev- ery gaming scenario, players bring their own sets of skills, knowledge, and previous experiences, which directly influence players' interpretations of game mechanics and in-game decision making. Players' knowledge structures have been characterized as sets of mental models, which are conceptualized as cognitive representations or mental simulations of real or imagined situations (Roskos-Ewoldsen, Roskos-Ewoldsen, \& Dillman Carpentier, 2002) that are formed through previous experiences, including both personal and mediated interactions. It has often been suggested that mental models have an analogical relationship to the situations they represent (Craik, 1943; Doyle \& Ford, 1998; Landriscina, 2013). In other words, the relations among entities in an individual's mental model of a certain situation should match the relations among entities in that situation. 
More specifically, mental models match individuals' perceptions of the relations among entities in that situation (Doyle \& Ford, 1998). As players interact with games, they construct, activate, and apply their mental models. This premise has served as the foundation for the application of a mental models approach to examining media effects, including those related to videogames (RoskosEwoldsen et al., 2002).

The mental model construct has been previously applied to a wide range of media related investigations, including: message effects (Cappella \& Street, 1989), political advertising (Biocca, 1991), game-based learning (Martinez-Garza \& Clark, 2017), and media priming (Roskos-Ewoldsen et al., 2002). The application of mental models in media effects studies has often revolved around the processing of visual images and their ability to create and activate related cognitive networks of associated ideas, concepts, or behaviors. Johnson-Laird and Byrne (1991) considered the iconic qualities of visual images that help individuals create associative cognitive networks for a given image, which then becomes linked to other iconic images and ultimately creates a mental model for a particular thing, person, event, etc. The results of these media priming studies have often been explained through the framework of mental models. Researchers argue that the accessibility of mental models may influence how media primes shape an individual's thoughts, such that more accessible mental models may shape the manner in which the media is perceived and interpreted (Roskos-Ewoldsen et al., 2002).

The process of efficient information processing as explained by researchers in their application of the mental models theory is based on the individual's ability to create and then access a network of linked models that are then utilized to make sense of new experiences based on a system of possibilities (Craik, 1943). Therefore, a direct or interactive experience with media provides a learning opportunity for users to evaluate the possibilities surrounding both existing and new mental models (Craik, 1943). Researchers posited that as a result of interactions with media, individuals draw inferences about their existing mental models and how they should respond or react to new related scenarios. Johnson-Laird (2005) describes this process as sentential reasoning, in which connectives such as "if" and "or" are used by the individual to help develop and advance their mental models based on new information. More recently, games researchers have sought to explore the foundations of these premises more closely, by focusing on the specific process in which a user's mental models are activated, utilized, and refined as part of a mediated experience (Martinez-Garza \& Clark, 2017). The emphasis of these explorations hinged on the process of how a users' existing mental models might be applied or aligned with the new game models being encountered in a gaming scenario. The fewer models an individual needs to rely on for an inference, the more efficient and effective their subsequent action should be (Johnson-Laird, 2005). This process is driven by a belief that spatial and temporal reasoning are likely to be improved when the individual can easily call upon related models (Byrne \& Johnson-Laird, 1989). Therefore, an individual's response to media is thought to be an outcome of the process in which individuals activate, construct, and apply their mental models. Depending on the individual's experiences and activation of those mental models, it is thought that some mental models become more or less accessible over time (Roskos-Ewoldsen et al., 2002).

Humans have a strong desire to expand their knowledge and understanding through controlled exploration (Kaplan, 1992). Humans also desire the opportunity to build upon their existing mental models in a manner that provides feedback and allows them to integrate new information into existing knowledge structures. Given these needs, games provide players a unique opportunity to learn and experience "new" things in a controlled and relatively safe environment. While the consumption of any media involves a variably active process of sensemaking, games go beyond more traditional media by requiring players to be active participants in the process (Bowman, 2018). In fact, researchers have examined players' alignment of their mental models with a game's mechanics in an effort to predict and explain the process by which players' mental models develop over time (Wasserman \& Bowman, 2018). Games allow players to interact, respond to, and shape the play experience, providing the raw materials for the mental models that are activated, developed, and/or refined over time. However, games are not just another media source for audiences to consume as narrative or visual media content; rather, the raw materials provided by game experiences are the interactive mechanical structures that change audiences into players (a more thorough discussion of game mechanics and their role in games is presented below). Therefore, the uniquely interactive experience that games provide allows researchers to specifically focus on the process by which an alignment of models occurs between a player and a game with an emphasis on how this process can predict and explain the effects of games, a process described as model matching (Boyan \& Sherry, 2011).

\subsection{Overview of Model Matching}

The primary aim of this article is to present the theoretical process of model matching. Before explicating each theoretical proposition in detail below, we overview the theory, which ultimately posits that: (a) greater alignment between a player's mental models and a game's mechanics better affords mental model transfer, and (b) mental model alignment and transfer influence a range of related outcomes, such as immersion (see Biocca, 1997), flow (see Sherry, 2004), ingame performance (see Ritter \& Schooler, 2001), learning (see Martinez-Garza \& Clark, 2017), and/or game transfer phenomena. 
Matching refers specifically to the extent and accuracy of alignment of a player's mental models with a game's constellation of mechanics. Game mechanics can be broadly described as the backbone of any game, or more specifically as the particular components that provide players possibilities for action within the game (Hunicke, LeBlanc, \& Zubek, 2004). Model matching and mental model development are iterative processes that occur incrementally over time. In this process, players apply their mental models to decision-making during gameplay and revise their mental models to reflect comparisons between predicted and observed outcomes (Landriscina, 2013). Through iterative refinement via gameplay and mental simulation, an individual's mental models should over time come to more closely match the relations among the game's mechanics (Boyan \& Sherry, 2011). In other words, the more players refine their mental models by comparing their observations to their mental simulations, the better their mental models correspond to the game mechanic system. By extension of this logic, when game mechanics represent a situation external to the game itself, mental models of the game may be applied to understanding its referent external situation (Martinez-Garza \& Clark, 2017). For example, in a realistic golf game, the better a player's mental model matches the interrelationships among golf club selection, golf balls, wind, and golf course characteristics, the more they should be able to apply this mental model to playing physical golf. Similarly, the greater fidelity with which games simulate external situations (i.e., situations not from a particular videogame per se), the more opportunity players should have to transfer preexisting mental models of the external situation to gameplay (Landriscina, 2013).

Model matching has been applied to a variety of contexts within the study of games (e.g., motion capturing controllers, McGloin, Farrar, \& Krcmar, 2011, 2013; exergaming, McGloin \& Embacher, 2017; game-based learning, Wasserman \& Banks, 2017). In addition to research explicitly applying model matching as a guiding framework, related scholarship supports the tenets and logic of model matching. Examples include studies of how mechanical game features impact players in a range of contexts, including: transfer from previous gaming experiences to new gameplay situations (Blumberg, Rosenthal, \& Randall, 2008), transfer from sports videogames to real-world sports situations (Downs \& Oliver, 2016), use of simulation games as training for pilots (Korteling et al., 2017), and the role of videogame playing experience in training laparoscopic surgeons (Rosser et al., 2007).

In sum, research into the process of model matching has tested assumptions regarding relationships among players' mental models, game mechanics, and external situations. However, there has been no formal attempt to organize the framework underlying this research into a set of specific guiding theoretical propositions. Formalizing model matching as a theory will provide researchers a unified explanation for a variety of game effects while also providing a theory-based direction for advancing the study of games. Therefore, the primary aim of this article is to provide an organized explanation of the model matching process and its theoretical propositions to formalize model matching as a theory.

\section{Model Matching Theoretical Propositions}

Given the application of the model matching framework to previous research, its congruence with existing research on the effects of gaming, and its potential for future development, we propose and explicate five propositions to formalize model matching as a theory. These theoretical propositions operate under the following boundary conditions:

(a) Model matching theory as formalized in this article applies only to mental models of game mechanics, which are distinct from-but likely related tomental models of non-mechanical game content (e.g., narrative structures, avatar appearances, fictional universes, social relationships);

(b) Individuals engage games in a goal-directed manner, utilizing or exploring game mechanics in the pursuit of some goal-e.g., overcoming ingame challenges or improving understanding of a game's mechanics.

\subsection{Proposition 1: Game Models Comprise a Collection of Game Mechanics that Provide Players with Affordances and Constraints for Game Action}

Game models are constituted by interconnected game mechanics that govern players' in-game actions by dictating what is and is not possible (Boyan \& Banks, 2017). Game mechanics are characterized in the context of the Mechanics, Dynamics, and Aesthetics (MDA) model, which provides a formal framework to game design and defines game mechanics as the "various actions, behaviors and control mechanisms afforded to the player within a game context" (Hunicke et al., 2004, p. 3). Game mechanics have three primary characteristics that are worth noting. First, game mechanics are impersonal. They react and respond in an identical fashion to the same inputs, regardless of individual players. Second, game mechanics are transparent. Individuals can play regardless of their depth of understanding of the game's mechanics. Third, game mechanics stand in for human action. For example, specific and often impractical tasks (e.g., reloading a weapon, picking up and/or carrying multiple items) are offloaded to the gaming system (see Boyan \& Banks, 2017).

Furthermore, game mechanics operate as individual affordances that provide opportunities and constraints for players' in-game behavior and decision making. Affordances in this context are what the game's mechanics offer the player as a means of interacting with the game environment, often but not always in an attempt to over- 
come the game's specific challenges. This conceptualization of affordance is based on Gibson's (1979) theory of affordances, which proposes that "the affordances of the environment are what it offers the animal, what it provides or furnishes, either for good or ill" (Gibson, 1979, p. 127). In the context of gameplay, game mechanics furnish players with options for action in the game environment. The resulting gameplay is a behavioral manifestation of the player's perception of and interaction with those mechanics or affordances (Hunicke et al., 2004). Ultimately, a player's relative success or failure in a game is a result of the player's interaction with the game's mechanics, as the player provides the input to specify the conditions and actions that influence the outcomes of the game.

Typically, numerous mechanics operate simultaneously within each game: input mechanics directly connect the game control scheme to action in the game avatar, mechanics regulate players' actions and limitations, and world mechanics dictate how non-player objects and characters interact. Each mechanic and their interconnections must be learned in order to master a game. Consider the popular Mario Kart family of Nintendo racing games. In most versions of Mario Kart, the directional pad/stick controls vehicle steering, one button accelerates, another button brakes, and yet another button controls the use of items. Players could complete a race only using the acceleration and directional buttons; however, if players want to succeed, they must engage the various mechanics in sync. Strategic acceleration into curves maximizes time spent at higher speeds, using items strategically can bolster one's position on the course, and advanced players can use the power-slide technique to reduce their track times.

Furthermore, it is typical to see certain game models copied or shared across similar games or genres. Designers integrate a common game mechanic in games that come from the same genre to help define the genre and give a common background for players interacting with a new game. In the Mario Kart example above, similar power-slide mechanics are present in many racing games. The exact control mechanics and physics may differ, but the basic existence and function of a power-slide is a part of many racing game models. By including shared mechanics across games, developers encourage players to cultivate, refine, and apply mental models across implementations of similar game mechanics (see Hunicke et al., 2004).

\subsection{Proposition 2: Players Create and Apply Mental Models as a Means of Making In-Game Decisions}

In order to navigate game models and pursue their goals in a game, players draw on their existing mental models and develop new mental models specific to a given game. During gameplay, players are presented with typically audiovisual cues that represent some entity or phenomenon. Players rely on these cues to activate cogni- tive networks related to the cues and their related constructs to help them identify an appropriate means of interaction. Initial application of existing mental models during gameplay begins with iconicity, or perceived similarity between a representation and the thing or concept that it represents (Bergman \& Paavola, n.d.). Game stimuli can activate existing mental models (a) by mere similarity, as when visual or auditory game features (e.g., the appearance of Mario) bring to mind an existing mental model that shares these features (e.g., of a previouslyplayed Mario game), or (b) by analogy, as when relationships among game features (e.g., a mini-map that diagrammatically represents in-game locations relative to an avatar's current location) bring to mind an existing mental model that shares these relationships (e.g., a map on a smartphone that diagrammatically represents geographic locations relative to an individual's current location). These existing mental models provide the basis for understanding a game. Iconicity allows players to access appropriate existing mental models as a means of providing a framework of possibilities for how these entities or phenomena may respond to different inputs (Craik, 1943). As a result, players activate a range of possibilities and determine which outcome provides the most effective solution.

Research on counterfactual processing provides empirical support for the application of mental models to making predictions and decisions. Gerstenberg, Peterson, Goodman, Lagnado and Tenenbaum (2017, p. 4) tested a counterfactual simulation model, which posits that individuals activate cognitive simulations comparing what has happened during an event with what would have happened if part of the cause had been absent or different. These cognitive simulations or "runnable mental models" are based on individuals' existing sets of knowledge structures on a given topic. Using eyetracking software, the researchers found support for their hypotheses that participants would compare what actually happened during a virtual game simulation of billiards balls striking each other with what would have happened had the balls not struck each other in the manner that they did. These findings indicated that individuals activated counterfactual mental models when sorting through their decision-making, suggesting that individuals rely on and apply existing mental models to evaluate possible outcomes in an effort to improve actions to achieve desirable outcomes.

Players' mental models are unique and independent from game models. The structure of a game and the particularities of players' actions during gameplay shape their subsequent mental representations (Laski \& Siegler, 2014; Siegler \& Ramani, 2009). However, mental models can originate from external situations in addition to game models. While game models likely influence the mental models players activate, individuals' responses to gaming stimuli are a byproduct of this activation process. For example, research on natural mapping motion capturing controllers suggests that game mechanics in- 
fluence which existing mental models players apply, with consequences for gameplay outcomes. Specifically, it has been found that players experienced greater immersion (McGloin et al., 2011, 2013) and enjoyment (McGloin et al., 2011) during gameplay when game controls for performing in-game behaviors were analogous to performing them out-of-game (i.e., swinging a tennis racket, throwing punches), compared to those players who utilized traditional game controllers with buttons and directional pads/joysticks. These findings suggest that players' existing mental models were better aligned with naturally mapped controllers than with traditional game controllers. In contrast, Bowman, Pietschmann and Liebold (2017) suggested that in certain gaming situations, players may have more developed mental models of traditional videogame controllers and thus may prefer traditional controllers to motion controllers. Collectively, these findings suggest that while mental models are not reducible to game models, players use their existing mental models, whether of sports or of gamepads, that best match a game's mechanics. As such, an individual's initial mental models provide a foundation for subsequent gameplay.

\subsection{Proposition 3: Players Refine Mental Models of Game Models through Repeated Engagements with a Game}

Individuals' existing mental models, whether of other games or external situations, may not always be $100 \%$ accurate and thus may not always align with a game in a fashion that produces the most desirable outcomes (see Craik, 1943; Doyle \& Ford, 1998). As players repeatedly engage with a game, they gradually refine their mental models such that their mental models tend to match game models more accurately. Players refine their mental models through an iterative process of trial and error (Boyan \& Sherry, 2011; Gee, 2007), capitalizing on the runnable or simulative nature of mental models (Craik, 1943). By (a) running mental models to generate predictions about the consequences of certain actions or potential future game states and (b) comparing these mental simulations to actualized outcomes, players can evaluate the reliability of their mental models for making accurate predictions. Simulating potential outcomes with mental models enables individuals to make predictions about the future (Battaglia, Hamrick, \& Tenenbaum, 2013) and to make counterfactual inferences about cause-and-effect (Gerstenberg et al., 2017). If predictions are accurate, we expect players' mental models will be reinforced. If predictions are inaccurate, we expect players' mental models will be modified based on the disconnect between their predictions and observations. Although players' engagement with games typically manifests as gameplay, it can also involve solitary practice or formal instruction (Charness, Tuffiash, Krampe, Reingold, \& Vasyukova, 2005), discussion of strategies among peers (Sharritt, 2008), or investiga- tion of underlying game mechanics (e.g., theorycrafting, Steinkuehler \& Duncan, 2008).

Games provide players three affordances in particular that support iterative mental model refinement. First, at a basic level, players can replay games in whole or in part, which offers players the ability to learn game models over time, even after making inaccurate predictions. For example, after failing a game objective, players are typically able to replay the game from the beginning or from a saved checkpoint. Failure can be productive for mental model refinement, particularly when failure prompts players to metacognitively appraise the disconnect between their mental models and game models and to subsequently acquire additional information to revise their mental models (Lee, Liu, Jullamon, \& Black, 2017). Second, many games gradually increase in difficulty, which scaffolds iterative learning by providing players cognitively manageable challenges along with doses of failure. Incrementally introducing elements of the game model enables players to test and retest limited components of their mental models, which improves players' performance when overcoming a game's challenges (Kopainsky, Alessi, Pedercini, \& Davidsen, 2015). Third, other players, whether opponents or teammates, player-controlled or artificial intelligence, provide additional resources for mental model refinement via vicarious learning. By observing the strategies of other players and their concomitant successes or failures, players can vicariously learn about effective (or ineffective) strategies that contribute to their understanding (Weintrop \& Wilensky, 2013).

Broadly, the more individuals play a particular game, the more closely their mental models match the game model (Wasserman \& Bowman, 2018). Further indirect evidence for iterative refinement of mental models manifests as learning curves of game performance (Ritter \& Schooler, 2001). Over time, as players repeatedly engage with games in various ways-including play, solitary and group practice, instruction, and the use of other resources-their skill and game performance gradually improve (Charness et al., 2005; Stafford \& Dewar, 2014). In line with the notion of productive failure, exploring the possibilities and limitations of game models supports mental model refinement during both initial encounters with a game and as players face later challenges. Although exploration may lead to short-term failure as players attempt unsuccessful strategies, early exploration of game models facilitates more successful long-term game performance (Stafford \& Dewar, 2014) and may be characteristic of more skilled players (Stafford, Devlin, Sifa, \& Drachen, 2017).

\subsection{Proposition 4: Alignment of Game Models and External Situations Can Facilitate the Player's Transfer of Mental Models between Game and External Situations}

The ability of individuals to transfer mental models between games and other non-game contexts, or exter- 
nal situations, is influenced by the degree of alignment between game models and external situations. Specifically, we posit that the closer a game model aligns with an external situation, the greater the potential for mental model transfer. Applying mental models of games to external situations relies on the capacity of game mechanics to simulate aspects of reality (Landriscina, 2013). Under ideal conditions, individuals should be able to apply their mental models of games to external situations to help structure their understanding of new information and to enact effective behaviors (see Korteling et al., 2017). This process should allow individuals the same predictive and interpretive capacities as proposed for model matching that takes place between different gameplay contexts.

The efficacy of this transfer process depends not only on (a) the match between mental models and game models, but also on (b) the accuracy of the match between a given game model and the external situation to/from which transfer is attempted (Martinez-Garza \& Clark, 2017). For example, transferring mental models of playing drums in a band to playing drums in a music videogame should be more successful the more accurately the gameplay resembles the process and activity of playing drums. In the reverse direction, game-based learning also exemplifies this process, in which transferring mental models from gameplay to academic contexts is the explicit goal (Boyan \& Sherry, 2011). For example, transferring mental models of microeconomics acquired from managing a business in a management game to an academic context should be more successful the more accurately the game model aligns with microeconomic principles. Indeed, number games with linear counting-on mechanics have been found to improve children's mental representations of number lines that transferred to subsequent arithmetic learning (Laski \& Siegler, 2014; Siegler \& Ramani, 2009).

Mental model transfer can take several specific forms. Individuals can apply their mental models wholesale to new contexts or, alternatively, individuals' existing mental models can heighten their sensitivity to particular elements, relationships, or dynamics in a given situation. As an example of wholesale mental model transfer, in a realistic F-16 flight simulator, in comparison to gamers who played civilian aircraft flight games, gamers who played an F-16 flight game performed better on simulation tasks specific to the F-16, but demonstrated less differences on more general flight-related simulation tasks (Korteling et al., 2017). As an example of transfer as heightened sensitivity to particular features, experts of the historical videogame Civilization exhibited deeper understandings of a college-level history textbook chapter than experts at the city building game SimCity-despite no prior differences in historical knowledge (Black, Khan, \& Huang, 2014). These findings suggest that playing games featuring mechanics that more closely match a particular transfer context (e.g., flying an F-16 or understanding historical processes) facilitates transfer of mental models from games to external situations. Mental model transfer also proceeds in the reverse direction, from external situations to games. For example, both prior videogaming experience and real-world driving experience have been found to enhance racing game performance among individuals with limited racing game experience (Koban, Liebold, \& Ohler, 2015), supporting the notion that individuals' preexisting mental models developed from both prior gameplay and real-world experience can be transferred to subsequent game encounters.

\subsection{Proposition 5: The Degree of Alignment of Mental Models to Game Models Impacts Media Effects}

In addition to the process by which players transfer their mental models between games and external situations, the degree of alignment between mental models and game models likely influences players' experiences and other effects associated with gameplay. That is, the degree to which players can overcome challenges with the mechanics given by a game model should influence other media effects. For example, if players cannot understand or overcome basic challenges in a game, it often becomes frustrating, leading to lower enjoyment (Sherry, Rosaen, Bowman, \& Huh, 2006). We posit that degree of alignment of mental models with game models should influence various gaming outcomes. The following examples are not meant to be exhaustive, but rather to exemplify the capacity of model matching theory to explain and predict established media effects.

Foremost, we posit that when mental models and game models are more closely aligned, players should exhibit more successful game performances. Improved performance is likely due in part to rejecting poorlyperforming alternative mental models that are less accurate and/or overly complex. As Johnson-Laird (2005) suggests: "The fewer the models needed for an inference, and the simpler they are, the less time the inference should take and the less prone it should be to error" (p. 193). In other words, by reducing the number and complexity of potential mental models, model matching yields faster and more accurate predictions, in turn yielding improved spatial and temporal reasoning (Byrne \& Johnson-Laird, 1989). In addition to having accurate mental models to choose from, experts in particular domains (i.e., those with more accurate mental models) recognize patterns and features intrinsic to game models that novices miss due to their orientations toward more superficial characteristics in problem solving (Leone, Fernandez Slezak, Cecchi, \& Sigman, 2014). Over time, experts have built mental models that integrate factual and deep domain knowledge with understandings of the relationships between the elements of a situation and likely outcomes in problem solving scenarios. Thus, players with more accurate mental models (i.e., experts) should perform better in games because of practice effects and a more efficient ability to cognitively search for information or solutions (Bogard, Liu, \& Chiang, 2013). 
Model matching theory can also predict and explain several media effects related to success in challenging and/or competitive gaming scenarios. Enjoyment is one result of the media flow state (Sherry, 2004), and flow theory contains several propositions that complement model matching theory. Flow is an experiential state characterized by extreme focus on an activity, loss of the sense of time passing, and feelings of enjoyment. Flow is thought to result from a balance between a person's skill in a given activity and the difficulty of the activity. When individuals engage in activities for which challenge and skill match, the resulting state is flow (Csikszentmihalyi, 1997). When an individual's skill exceeds the challenge, the result is boredom, and when challenge exceeds an individual's skill, the result is frustration. Only in the intermediate zone where skill and challenge match does flow occur. Alignment of mental models with game models likely plays a role in this process. As aforementioned, game challenges are intimately related to game models, and players' skills are a product of their mental models. Thus, alignment between game models (a source of challenge) and mental models (a source of skill) should increase enjoyment, immersion, and other flow state-related experiences (McGloin, Farrar, Krcmar, Park, \& Fishlock, 2016).

Of particular interest to media scholars is how model matching theory might complement existing approaches to studying game effects, especially models that attempt to address the effects of videogame content on player thoughts and behaviors. For example, the general aggression model (GAM) has been widely used as an approach for understanding the impacts of videogame content on particular kinds of outcomes related to aggression (Bushman \& Anderson, 2002). Predictions using GAM differ from model matching theory in that GAM studies have focused primarily on the game's audiovisual content as opposed to the game's mechanics. Researchers applying a GAM-based approach typically contrast games with similar mechanics but different on-screen content, such as a driving game with either a gun or a tennis racket in the passenger seat (Bushman, Kerwin, Whitlock, \& Weisenberger, 2017). In these studies, research questions are focused on the meaning-making of the (aggressive) content of the game or media, which is derived from GAM's theoretical underpinning in schema theory (Bushman \& Anderson, 2002).

Schema theory posits that individuals build knowledge structures in the form of relatively static, stable guides for reactions to regular and routine situations, or scripts, out of stimuli they encounter (Jones, Ross, Lynam, Perez, \& Leitch, 2011). GAM proposes that as players observe aggressive media content over time, they integrate those violent actions into their schemas of appropriate responses to confrontational situations. This approach aligns closely with schema theory, which posits that individuals observe and update scripts in order to obtain behavioral guidance for general life scenarios. Model matching theory differs from GAM in its emphasis on in- teraction with game mechanics rather than audiovisuals, and on mental models rather than schemas.

Mental models are conceptually similar but distinct from schemas. Whereas schemas are relatively generic, relatively static templates for how to behave and the events that occur in a type of situation or context, mental models are more precise dynamic mental simulations of spatiotemporal, logical, and causal relationships in a particular situation (Jones et al., 2011). This emphasis on mental models in model matching theory is tied to the centrality of game mechanics and interactivity in games. Game mechanics constitute the spatiotemporal, logical, and causal relationships in the game model with which players interact during gameplay. By centering game mechanics and interactivity, model matching theory is distinct from GAM and other more observation-based learning theories that have been applied to gameplay outcomes (e.g., transportation imagery model, social cognitive theory) in its emphasis on characteristics of games that are relatively distinct from other media.

\subsection{Testing Model Matching Theory's Propositions in Future Research}

In order to further advance model matching theory as currently formulated, in addition to aforementioned literature that supports these propositions, researchers will need to further evaluate the theory's formalized propositions with a focus on how alignment between mental models, game models, and external situations influence particular outcomes. Recent literature examining cognitive skill acquisition and videogaming suggests gaming skills often do not transfer to external situations (Sala, Tatlidil, \& Gobet, 2017). Model matching theory's emphasis on mental models of game models (i.e., constellations of game mechanics) may provide a way forward for understanding conditions under which transfer is more or less likely. Characteristics of game models should also be evaluated for their ability to promote greater alignment of mental models of games with mental models of external situations, which could facilitate the transfer of game-related mental models and promote outcomes related to direct learning.

Research into how differences among players' mental models influence the alignment process is also needed. Specifically, researchers may look to see how prior experience with a game genre influences initial alignment of mental models and game models, as well as the rate of subsequent improvement. Along similar lines, investigations related to the process in which mental models are developed are also needed. Does engaging in multiple iterations of gameplay allow players to more accurately align their mental models to game models, as well as to transfer those mental models to other contexts more easily or successfully?

In addition to the theory's testability, it may also be useful in explaining why certain outcomes or effects have taken place. Games designed to enhance learning or in- 
crease a player's skill set related to some external situation may have varying effects depending on how well the player was able to align their existing mental models to the game model. Thus, model matching theory may be useful to researchers seeking a theoretical explanation for why certain games or encounters with games are only capable of increasing learning related outcomes for some players but not all. What traits, practices, or cognitive orientations promote more rapid and/or more accurate model matching? From a more meta-analytic perspective, researchers may wish to synthesize studies consistent with model matching theory to determine how varying degrees of alignment among mental models, game models, and external situations influence aforementioned outcomes. For researchers examining the influence of technological affordances (e.g., virtual reality, kinesic inputs) on gaming experiences, model matching theory may provide a means of predicting and explaining the influence that these affordances have on the individual's ability to align and refine their mental models with the game's models.

Finally, future research should probe the boundary conditions of the theory to identify fruitful alterations or expansions. Specifically, the appropriateness of applying model matching beyond the boundary condition of mechanical game content could be tested to determine if the theory may be parsimoniously expanded to apply to non-mechanical game content as well. During future theory development, it will be critical to specify whether and how the process of mental model utilization and revision differ between game mechanics and nonmechanics. For example, does model matching apply to gameplay during which game mechanics are not central to a player's decision-making process? Roleplaying and/or world building scenarios may present unique contexts for examining whether model matching is applicable to engagement with non-mechanical game content, and if so, how it may differ from engaging a game's mechanics. The appropriateness of applying model matching beyond the boundary condition of players actively engaging the game with deliberative purpose should also be probed. Players may often interact with a game less deliberately, as when they rely on simple heuristics to progress through the game rather than mental model simulations (Martinez-Garza \& Clark, 2017). Thus, future research will need to examine if/how a player's intentions (e.g., deliberative attempts to overcome challenges versus non-deliberative exploration) influence the model matching process.

\section{Conclusion}

Model matching theory focuses on the process through which players align and match their preexisting knowledge structures with a game's mechanics in an effort to overcome the game's challenges. Model matching theory makes specific predictions about how players will revise their mental models and how the match between a game model and an external model can have an influ- ence on the effects of the gaming experience as well as its ability to influence outcomes related to mental model transfer. Model matching theory also provides a theoretical framework for scholars to explore new questions about games and their effects. The propositions laid out in this article are intended to serve as the primary tenets of model matching theory, and therefore these tenets must be tested in future research as a means of evaluating and refining them.

Model matching theory describes a process with which game studies scholars can examine dynamic interactions of players and game mechanics to predict and explain how the alignment of game models, mental models, and external situations influences transfer of mental models to external situations and application to real world situations. By emphasizing the role of cognitive mental models of game mechanics, model matching theory provides a foundation for researchers to investigate the effects of games utilizing a dynamic perspective that emphasizes the interactive nature of games.

\section{Acknowledgments}

The authors would like to thank Dr. Jaime Banks for providing critical feedback during the preparation of this manuscript.

\section{Conflict of Interests}

The authors declare no conflict of interests.

\section{References}

Battaglia, P. W., Hamrick, J. B., \& Tenenbaum, J. B. (2013). Simulation as an engine of physical scene understanding. Proceedings of the National Academy of Sciences, 110, 18327-18332. doi:10.1073/ pnas. 1306572110

Bergman, M., \& Paavola, S. (Eds.). (n.d.). Icon. The Commens dictionary: Peirce's terms in his own words. Retrieved from http://www.commens.org/dictionary/ term/icon

Biocca, F. (1991). Viewers' mental models of political ads: Towards a theory of the semantic processing of television. In F. Biocca (Ed.), Television and political advertising: Vol 1. Psychological processes (pp. 27-91). Hillsdale, NJ: Lawrence Erlbaum Associates.

Biocca, F. (1997). The cyborg's dilemma: Progressive embodiment in virtual environments. Journal of Computer-Mediated Communication, 3. doi:10.1111/j.1083-6101.1997.tb00070.x

Black, J. B., Khan, S. A., \& Huang, S.-C. D. (2014). Video and computer games as grounding experiences for learning. In J. Asbell-Clarke (Ed.), Learning by playing: Video gaming in education (pp. 290-301). New York, NY: Oxford University Press.

Blumberg, F. C., Rosenthal, S. F., \& Randall, J. D. (2008). Impasse-driven learning in the context of video 
games. Computers in Human Behavior, 24, 15301541. doi:10.1016/j.chb.2007.05.010

Bogard, T., Liu, M., Chiang, Y. H. V. (2013). Thresholds of knowledge development in complex problem solving: A multiple-case study of advanced learners' cognitive processes. Educational Technology Research and Development, 61, 465-503. doi: 10.1007/s11423-0139295-4

Bowman, N. D., Pietschmann, D., \& Liebold, B. (2017). The golden (hands) rule: Exploring user experiences with gamepad and natural-user interfaces in popular video games. Journal of Gaming \& Virtual Worlds, 9, 71-85. doi: 10.1386/jgvw.9.1.71_1

Bowman, N. D. (2018). The demanding nature of video game play. In N. D. Bowman (Ed.), Video games: A medium that demands our attention (pp. 1-24). New York, NY: Routledge.

Boyan, A., \& Sherry, J. L. (2011). The challenge in creating games for education: Aligning mental models with game models. Child Development Perspectives, 5, 82-87. doi:10.1111/j.1750-8606.2011.00160.x

Boyan, A., \& Banks, J. (2017). Rules \& mechanics: Parameters for interactivity. In J. Banks (Ed.), Avatar, assembled: The social and technical anatomy of digital bodies (pp. 159-168). New York, NY: Peter Lang.

Bushman, B. J., \& Anderson, C. A. (2002). Violent video games and hostile expectations: $A$ test of the general aggression model. Personality and Social Psychology Bulletin, 28, 1679-1686. doi: 10.1177/ 014616702237649

Bushman, B. J., Kerwin, T., Whitlock, T., \& Weisenberger, J. M. (2017). The weapons effect on wheels: Motorists drive more aggressively when there is a gun in the vehicle. Journal of Experimental Social Psychology, 73, 82-85. doi:10.1016/j.jesp.2017.06.007

Byrne, R. M. J., \& Johnson-Laird, P. N. (1989). Spatial reasoning. Journal of Memory and Language, 28, 564-575. doi:10.1016/0749-596X(89)90013-2

Cappella, J. N., \& Street, R. L., Jr. (1989). Message effects: Theory and research on mental models of messages. In J. J. Bradac (Ed.), Message effects in communication science (pp. 24-51). Newbury Park, CA: Sage.

Charness, N., Tuffiash, M., Krampe, R., Reingold, E., \& Vasyukova, E. (2005). The role of deliberate practice in chess expertise. Applied Cognitive Psychology, 19, 151-165. doi:10.1002/acp.1106

Craik, K. (1943). The nature of explanation. Cambridge: Cambridge University Press.

Csikszentmihalyi, M. (1997). Finding flow: The psychology of engagement with everyday life. New York, NY: Basic Books.

Downs, E., \& Oliver, M. B. (2016). How can Wii learn from video games? Examining relationships between technological affordances and socio-cognitive determinates on affective and behavioral outcomes. International Journal of Gaming and ComputerMediated Simulation, 8, 28-34. doi:10.4018/ IJGCMS.2016010103
Doyle, J. K., \& Ford, D. N. (1998). Mental models concepts for system dynamics research. System Dynamics Review, 14, 3-29.

Gee, J. P. (2007). What video games have to teach us about learning and literacy. New York, NY: Palgrave Macmillan.

Gerstenberg, T., Peterson, M. F., Goodman, N. D., Lagnado, D. A., \& Tenenbaum, J. B. (2017). Eye-tracking causality. Psychological Science, 28, 1731-1744. doi:10.1177/0956797617713053

Gibson, J. J. (1979). The theory of affordances. In R. E. Shaw \& J. Bransford (Eds.), Perceiving, acting, and knowing: Toward an ecological psychology (pp. 67-82). Hillsdale, NJ: Lawrence Erlbaum Associates.

Green, C. S. (2018). Video games and cognitive skills. In N. D. Bowman (Ed.), Video games: A medium that demands our attention (pp. 25-43). New York, NY: Routledge.

Hunicke, R., LeBlanc, M., \& Zubek, R. (2004). MDA: A formal approach to game design and game research. In Challenges in Game Artificial Intelligence: Papers from the 2004 AAAI Workshop (pp. 1-5). Menlo Park, CA: The AAAI Press.

Johnson-Laird, P. N., \& Byrne, R. M. J. (1991). Deduction. Hillsdale, NJ: Lawrence Erlbaum Associates.

Johnson-Laird, P. N. (2005). Mental models and thought. In K. J. Holyoak \& R. G. Morrison (Eds.), The Cambridge handbook of thinking and reasoning (pp. 185-208). Cambridge: Cambridge University Press.

Jones, N., Ross, H., Lynam, T., Perez, P., \& Leitch, A. (2011). Mental models: An interdisciplinary synthesis of theory and methods. Ecology and Society, 16(1). doi: 0.5751/ES-03802-160146

Kaplan, S. (1992). Environmental preference in a knowledge seeking knowledge using organism. In J. H. Barkow, L. Cosmides, \& J. Tooby (Eds.), The adaptive mind (pp. 535-552). New York, NY: Oxford University Press.

Koban, K., Liebold, B., \& Ohler, P. (2015). Good newbie or poor newbie? Determinants of video game skill acquisition at an early stage. In Learning and collaboration technologies (pp. 608-619). Cham: Springer. doi:10.1007/978-3-319-20609-7_57

Kopainsky, B., Alessi, S. M., Pedercini, M., \& Davidsen, P. I. (2015). Effect of prior exploration as an instructional strategy for system dynamics. Simulation \& Gaming, 46, 293-321. doi:10.1177/1046878113517536

Korteling, H. J. E., Helsdingen, A. S., \& Sluimer, R. R. (2017). An empirical evaluation of transfer-oftraining of two flight simulation games. Simulation \& Gaming, 48, 8-35. doi:10.1177/1046878116671057

Landriscina, F. (2013). Simulation and learning: A modelcentered approach. New York, NY: Springer.

Laski, E. V., \& Siegler, R. S. (2014). Learning from number board games: You learn what you encode. Developmental Psychology, 50, 853-864. doi:10.1037/ a0034321

Lee, A., Liu, C., Jullamon, M., \& Black, J. (2017). How'd 
that happen?! Failure in game spaces to prepare students for future learning. In K. E. H. Caldwell, S. Seyler, A. Ochsner, \& C. Steinkuehler (Eds.), GLS conference proceedings 2017 (pp. 119-128). Pittsburgh, PA: Carnegie Mellon ETC Press.

Leone, M. J., Fernandez Slezak, D., Cecchi, G. A., \& Sigman, M. (2014). The geometry of expertise. Frontiers in Psychology, 5. doi:10.3389/fpsyg.2014.00047

Martinez-Garza, M. M., \& Clark, D. B. (2017). Two systems, two stances: A Novel theoretical framework for model-based learning in digital games. In P. Wouters \& H. van Oostendorp (Eds.), Instructional techniques to facilitate learning and motivation of serious games (pp. 37-58). Cham: Springer International Publishing.

McGloin, R., \& Embacher, K. (2017). "Just like riding a bike": A model matching approach to predicting the enjoyment of a cycling exergame experience. Media Psychology. doi:10.1080/15213269.2017.1311269

McGloin, R., Farrar, K. M., \& Fishlock, J. (2015). Triple whammy! Violent games and violent controllers: Investigating the use of realistic gun controllers on perceptions of realism, immersion, and outcome aggression. Journal of Communication, 65, 280-299. doi:10.1111/jcom.12148

McGloin, R., Farrar, K., \& Krcmar, M. (2011). The impact of controller naturalness on spatial presence, gamer enjoyment, and perceived realism in a tennis simulation video game. Presence: Teleoperators and Virtual Environments, 20, 309-324. doi:10.1162/ PRES_a_00053

McGloin, R., Farrar, K., \& Krcmar, M. (2013). Video games, immersion, and cognitive aggression: Does the controller matter? Media Psychology, 16, 65-87. doi:10.1080/15213269.2012.752428

McGloin, R., Farrar, K., Krcmar, M., Park, S., \& Fishlock, J. (2016). Modeling outcomes of violent video game play: Applying mental models and model matching to explain the relationship between user differences, game characteristics, enjoyment, and aggressive intentions. Computers in Human Behavior, 62, 442-451. doi:10.1016/j.chb.2016.04.018

Oliver, M. B., Bowman, N. D., Woolley, J. K., Rogers, R., Sherrick, B. I., \& Chung, M.-Y. (2016). Video games as meaningful entertainment experiences. Psychology of Popular Media Culture, 5, 390-405. doi:10.1037/ ppm0000066

Ritter, F. E., \& Schooler, L. J. (2001). The learning curve. In N. J. Smelser \& P. B. Baltes (Eds.), International encyclopedia of the social \& behavioral sciences (pp. 8602-8605). Oxford: Pergamon. doi:10.1016/B0-08043076-7/01480-7

Roskos-Ewoldsen, D. R., Roskos-Ewoldsen, B., \& Dillman Carpentier, F. R. (2002). Media priming: A synthesis. In J. B. Bryant \& D. Zillmann (Eds.), Media effects in theory and research, second edition (pp. 97-120). Mahwah, NJ: Lawrence Erlbaum Associates.

Rosser, J. C., Lynch, P. J., Cuddihy, L., Gentile, D. A., Klonsky, J., \& Merrell, R. (2007). The impact of video games on training surgeons in the 21st century. Archives of Surgery, 142, 181-186. doi:10.1001/ archsurg.142.2.181

Sala, G., Tatlidil, K. S., \& Gobet, F. (2017). Video game training does not enhance cognitive ability: A comprehensive meta-analytic investigation. Psychological Bulletin, 144, 111-139. doi:10.1037/bul0000139

Sharritt, M. J. (2008). Forms of learning in collaborative video game play. Research and Practice in Technology Enhanced Learning, 3, 97-138. doi:10.1142/ S1793206808000471

Sherry, J. L. (2004). Flow and media enjoyment. Communication Theory, 14, 328-347. doi:10.1111/j.14682885.2004.tb00318.x

Sherry, J. L., Rosaen, S., Bowman, N. D., \& Huh, S. (2006, May). Cognitive skill predicts video game ability. Paper presented at the annual meeting of the International Communication Association. Dresden, Germany.

Siegler, R. S., \& Ramani, G. B. (2009). Playing linear number board games-but not circular ones-improves low-income preschoolers' numerical understanding. Journal of Educational Psychology, 101, 545-560. doi:10.1037/a0014239

Stafford, T., Devlin, S., Sifa, R., \& Drachen, A. (2017). Exploration and skill acquisition in a major online game. In Proceedings of the 39th Annual Meeting of the Cognitive Science Society (pp. 3249-3254).

Stafford, T., \& Dewar, M. (2014). Tracing the trajectory of skill learning with a very large sample of online game players. Psychological Science, 25, 511-518. doi:10.1177/0956797613511466

Steinkuehler, C., \& Duncan, S. (2008). Scientific habits of mind in virtual worlds. Journal of Science Education and Technology, 17, 530-543. doi:10.1007/s10956008-9120-8

Wasserman, J. A., \& Banks, J. (2017). Details and dynamics: Mental models of complex systems in gamebased learning. Simulation \& Gaming, 48, 603-624. doi:10.1177/1046878117715056

Wasserman, J. A., \& Bowman, N. D. (2018, June). Bugs on the brain: A mental model matching approach to cognitive skill acquisition in a strategy game. Paper presented at the annual meeting of the International Communication Association. Prague, Czech Republic.

Weintrop, D., \& Wilensky, U. (2013). Know your enemy: Learning from in-game opponents. In Proceedings of the 12th international conference on interaction design and children (pp. 408-411). New York, NY: ACM. doi:10.1145/2485760.2485789 


\section{COGITATIO}

\section{About the Authors}
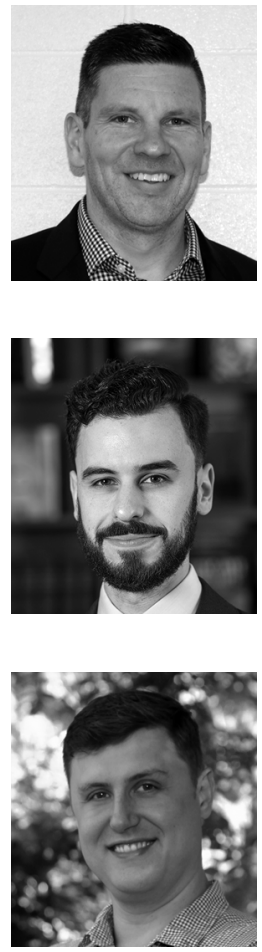

Rory McGloin (PhD, University of Connecticut) is an assistant professor in the Department of Communication at the University of Connecticut. Dr. McGloin's research centers around perceptions of interactive media experiences, with a particular emphasis on of motion based control systems and their influence on feelings of immersion and enjoyment. Dr. McGloin's more recent research has begun to examine the use of exer-gaming devices as a means of increasing positive attitudes towards physical activity amongst youth populations.

Joe A. Wasserman (MA, West Virginia University) is a doctoral student in the Department of Communication Studies at West Virginia University, where he is an Arlen G. and Louise Stone Swiger Fellow and the Lab Manager of the Interaction Lab (\#ixlab). His research is on learning via gameplay, with an emphasis on systems thinking outcomes and the role of game modality in playing and learning processes.

Andy Boyan (PhD, Michigan State University) is Chair of the Communication Studies Department at Albion College in Michigan. His scholarship focuses on digital media system features and how they influence individual, group, and social user interactions. His recent work examines blockchain network and cryptocurrency systems as emerging features of digital technology, as well as game and other digital media systems and their ability to teach mechanics. 